\title{
EDITORIAL
}

\section{THE FLORENCE NETWORK PROMOTES INTERCULTURAL COOPERATION IN THE EDUCATION OF NURSES AND MIDWIFES}

\author{
Jana Nemcová \\ Department of Nursing, Jessenius Faculty of Medicine in Martin, Comenius University Bratislava, Slovakia
}

Forming awareness of the importance and recognition of the nursing and midwifery professions is also of concern to the Florence Network, a European higher education cooperation that currently brings together teachers and students from 48 universities in 21 European countries. Since its inception in 1995, the Florence Network has promoted mobility under the Erasmus Programme, with the aim to help students get together, share experiences, deepen their mutual understanding and remove barriers in culturally different settings. The intercultural diversity of practice, experienced during exchange programmes involving European universities, teaches students to be tolerant and flexible. Students learn from positive examples that motivate them for their future careers as nurses or midwives. Their self-confidence and sense of belonging to the profession are strengthened, which is crucial for stability and staying in their jobs and also in view of the current shortage of nurses.

The Florence Network also has an ambition to unite and standardize nursing and midwifery education in European Union countries. Teachers, members of the Florence Network, support each other in promoting the humane nursing model in education. Teacher exchanges, resulting also from contacts made through the Florence Network, are not only important for their professional growth but also generally beneficial for the process of nursing and midwifery education, with an emphasis on education based on modern didactic methods, a close connection between theory and practice and use of the latest digital technologies.
The intellectual background provided by teachers, members of the Florence Network, also makes it possible to share research outcomes and provides space for the development of collaboration on joint research and educational projects. Projects involving teachers and students, members of the Florence Network, have a global impact on the development of education, practice and research in nursing and midwifery at both national and international levels.

International cooperation, as a key phenomenon in the Florence Network's activities, continues despite the difficult time of the COVID-19 pandemic. This was proven by a Florence Network online meeting held in May 2021 to share experiences with nursing education and practice during the pandemic. Presented were the visions of university and intercultural education, practice and research in nursing and midwifery for ensuring Global Human Security, the main topic of the Florence Network virtual meeting.

Intercultural exchange of experiences, understanding and tolerance, as important attributes of the Florence Network, are an investment in maintaining high credibility in professional training of future nurses and midwives throughout Europe.

Jana Nemcová, PhD, RN President of the Florence Network e-mail: jana.nemcova@uniba.sk 